\title{
Tonsillar metastasis of oesophageal adenocarcinoma
}

\author{
Bram Struijs • Remco de Bree • \\ Cornelis J. van Groeningen · Wolter J. Mooi · \\ C. René Leemans
}

Received: 19 January 2007 / Accepted: 10 July 2007 / Published online: 27 July 2007

(C) Springer-Verlag 2007

\begin{abstract}
In the literature less than 100 cases of metastatic carcinoma of the palatine tonsil have been reported. Tonsillar metastasis of adenocarcinoma of the oesophagus has not been reported previously. We report a case of a 57year-old male with a primary adenocarcinoma of the distal esophagus with a metastasis in the right palatine tonsil. Metastatic tumour involving the palatine tonsil is rare. The route of dissemination remains unclear. Hypothetically the dissemination of tumour cells could be lymphogenic or secondary by transportation due to vomiting or at the time of endoscopy, but most likely represents haematogenous spread.
\end{abstract}

Keywords Tonsil · Metastasis - Adenocarcinoma .

Oesophagus $\cdot$ Head and neck

\section{Introduction}

The vast majority of cancers in the head and neck region are of epithelial origin. Lymphoma is the next most common malignancy in this area. Metastases in the head and neck other than lymph node metastases are rare.

B. Struijs · R. de Bree $(\varangle) \cdot$ C. René Leemans Department of Otolaryngology and Head and Neck Surgery,

VU University Medical Center, De Boelelaan 1117,

1081 HV Amsterdam, The Netherlands

e-mail: r.bree@vumc.nl

\section{J. van Groeningen}

Department of Medical Oncology,

VU University Medical Center, Amsterdam, The Netherlands

W. J. Mooi

Department of Pathology, VU University Medical Center, Amsterdam, The Netherlands
The occurrence of tonsillar metastases from non-haematological malignant neoplasms is very rare [10]. We present a patient with metastasis in the right tonsil of a primary adenocarcinoma of the distal oesophagus.

\section{Case report}

A 57-year-old man was referred to our department of otolaryngology and head and neck surgery, because of dysphagia, pain and swelling of the right palatine tonsil. He also complained of frequent vomiting. Five months previously, an adenocarcinoma of the distal oesophagus with lymph node and liver metastases had been diagnosed. He received chemotherapy with combined capecitabine and oxaliplatin, which was stopped after two cycles because of disease progression. On physical examination an enlarged and ulcerating right palatine tonsil was seen (Fig. 1). A suspicious ipsilateral cervical lymph node of $2 \times 4 \mathrm{~cm}$ was found at level II. A biopsy of the tonsillar tumour was performed and revealed intestinal-type adenocarcinoma. The histopathological picture corresponded with that of the oesophageal tumour (Fig. 2). Tonsillectomy was not performed because of severe clotting disorders attributed to liver metastases. The patient died 4 weeks after his first visit to our department.

\section{Discussion}

Second primary tumours relatively often involve the head and neck region. These tumours develop in head and neck cancer patients due to their common factors in carcinogenesis, e.g., tobacco, alcohol and, probably, genetic susceptibility [4]. However, this common aetiology applies for 


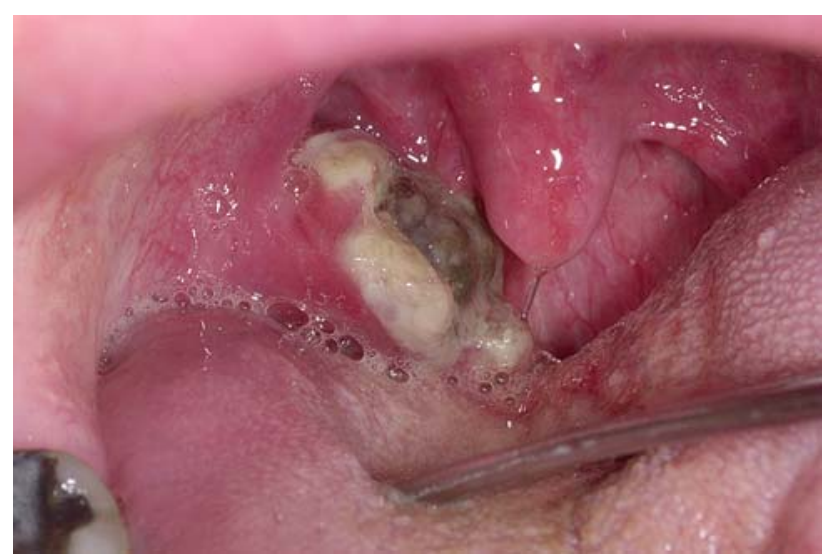

Fig. 1 Enlarged right palatine tonsil with ulceration

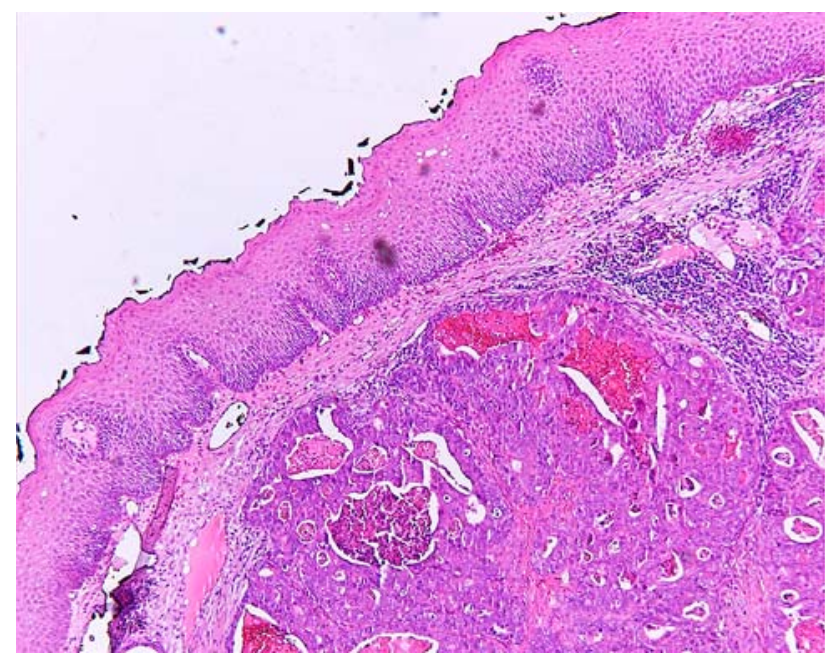

Fig. 2 Biopsy right tonsil: adenocarcinoma (intestinal type)

squamous cell carcinoma and not for adenocarcinoma. Simultaneous primary adenocarcinomas are not frequently found. In our patient the corresponding histopathology indicates a common origin, suggesting metastatic disease.

Primary oesophageal adenocarcinoma is a relatively uncommon tumour in western countries [9]. The pattern of metastasis of oesophageal adenocarcinoma can be lymphogenic, haematogenic and by transportation of tumour cells by regurgitation or endoscopes [2, 10]. Lymphogenic spread of distal oesophageal adenocarcinoma generally involves the regional nodes in the lower posterior mediastinum, the paracardiac region, along the lesser curvature and the left gastric artery [6]. In case of extensive lymphogenic spread, lymph-node metastases can be found in the tracheal bifurcation region, the proximal mediastinum, coeliac axis and supra-clavicular region [6]. Lymphogenic spread of adenocarcinoma of the distal oesophagus and the gastrooesophageal junction is present in $70 \%$ of the patients at the time of diagnosis of the primary tumour [9].
Haematogenous dissemination occurs at a later stage and is less frequent. Liver and lung are the most common organs involved [6].

Metastatic tumour involving the palatine tonsil is distinctly rare. These metastases represent only $0.8 \%$ of all tonsillar tumours [5]. Bilateral metastases of gastric carcinoma to the tonsils have been described [7]. Less than 100 cases of metastatic carcinoma of the palatine tonsil have been reported [3, 7]. The most frequent tumours metastasizing to the tonsil are melanoma, lung carcinoma, breast carcinoma and renal cell carcinoma [3]. Eleven cases were associated with gastric adenocarcinoma [2, 7, 8]. Tonsillar metastasis of adenocarcinoma of the esophagus has not been reported previously. The occurrence of a tonsillar metastasis as the first manifestation of an occult neoplasm is very unusual [8]. In the majority of cases the occurrence of a tonsillar metastasis becomes manifest after the diagnosis of the primary tumour and is generally part of a widespread systemic disease [2]. Therefore, mean survival time for patients with tonsillar metastases is short, with a mean of 9 months, irrespective of the histological type of primary tumour [3].

In this case there are four hypothetical pathways for metastatic spread to the tonsils: Haematogenous dissemination of tumour from an esophageal carcinoma may occur via the portal circulation, the liver, the pulmonary circulation and systemic arterial vessels, thus reaching the palatine tonsil. A second haematogenous route may be through the paravertebral plexus of Batson, bypassing the lungs [1]. Retrograde flow via this valveless plexus occurs during elevated intra-abdominal and intrathoracic pressure, as is brought about by straining, coughing or as in this case, vomiting [1]. A third route of metastasis may be through the thoracic duct followed by retrograde cervical lymphatic spread to the tonsil [3]. This route of dissemination is very rare and is mostly seen in cases of seminomas [3]. Finally, some authors believe the possibility of metastasis by direct translumenal implantation, which might be favoured by a previous lesion in the mucosa of the tonsil [2]. The tumour cells would be transported secondary to regurgitation from the oesophagus [8], or as in this case possibly because of frequent vomiting, or at the time of endoscopy [2].

In conclusion, when finding a tumour of the tonsil a metastasis from a distant primary malignancy should be considered, although this is very rare. The route of dissemination eventually remains unclear.

\section{References}

1. Batson OV (1942) The role of the vertebral veins in metastatic process. Ann Intern Med 16:38-45

2. Benito I, Alvarez-gago T, Morais D (1996) Tonsillar metastasis from adenocarcinoma of the stomach. J laryngol Otol 110:291-293 
3. Brownson RJ, Jaques WE, Lamonte SE, Zollinger WK (1979) Hypernephroma metastatic to the palatine tonsils. Ann Otol Rhinol Laryngol 88:235-240

4. Cloos J, Spitz MR, Schantz SP et al (1996) Genetic susceptibility to head and neck squamous cell carcinoma. J Natl Cancer Inst 88:530-535

5. Crawford BE, Callihan MD, Corio RL, Hyams VJ, Karnei RF (1979) Symposium on malignant disease of the oral cavity and related structures. Otolaryngol Clin North Am 12:29-43

6. Feith M, Stein HJ, Siewert JR (2003) Pattern of lymphatic spread of Barrett's cancer. World J Surg 27:1052-1057
7. Gallo A, Pescarmona E, Crupi J, Corsetti GL, De Vincentiis M (1992) Bilateral tonsillar metastasis of gastric adenocarcinomas. Head Neck Surg 14:55-57

8. Hurlstone DP, Sanders DS, Smith A, Jones RB, Slater DN, Bardhan KD (2001) Tonsillar metastasis: a rare presentation of gastric carcinoma. Eur J Surg Oncol 27(3):328-330

9. Juan Sánchez Jiménez et al (2005) Metastatic tumours in upper maxillary bone of esophageal adenocarcinoma. A case report. Med Oral Patol Oral Cir Bucal 10:252-257

10. Kleinschmidt HJ (1966) Tonsillen Metastasen bei primaren Bronchial- und Magenkarzinom. Z Laryngol Rhinol Otol 45:389-394 